\title{
Kohesi Gramatikal dan Kohesi Leksikal dalam Kumpulan Cerpen Konvensi Karya A. Mustofa Bisri
}

\author{
Sanajaya ${ }^{1)}$ \\ Universitas Indraprasta PGRI \\ Jalan Nangka No. 58 C/TB. Simatupang, Tanjung Barat, Jakarta Selatan 12530 \\ Gustaman Saragih ${ }^{2)}$ \\ Universitas Indraprasta PGRI \\ Jalan Nangka No. 58 C/TB. Simatupang, Tanjung Barat, Jakarta Selatan 12530 \\ Restoeningroem $^{3)}$ \\ Universitas Indraprasta PGRI \\ Jalan Nangka No. 58 C/TB. Simatupang, Tanjung Barat, Jakarta Selatan 12530 \\ Sanajaya9@gmail.com ${ }^{1)}$
}

\begin{abstract}
This study aims to find (1) aspects of grammatical cohesion in the collection of convention short stories by A. Mustofa Bisri and (2) aspects of lexical cohesion in the collection of convention short stories by A. Mustofa Bisri. The data collection technique used was listening, engaging, speaking, and taking notes. The data analysis technique used in this study is a split technique with basic techniques for direct elements (BUL) and the advanced techniques used are the lesion technique and the dressing technique. After conducting the research, the researcher found several findings, as follows; (1) Grammatical cohesion in this study found 109 data with the following details; reference aspects are 99 data or $91 \%$, conjunction as much as 8 data or 7\%, ellipsis as much as 2 data or $2 \%$, and substitution of 0 data or $0 \%$. Meanwhile (2) there were 26 lexical cohesion with the following details; repetition aspect is 6 data or 23\%, synonym is 6 data or 23\%, antonym is 6 data or $23 \%$, the equivalent is 4 data or $15 \%$. hyponymy is 2 data or $8 \%$, and collocation is 2 data or $8 \%$. Each aspect of cohesion, both grammatical and lexical cohesion, has a role in the formation of text in discourse, so that discourse can be coherently structured.
\end{abstract}

Keywords: Grammatical cohesion, lexical cohesion, short story.

\begin{abstract}
Abstrak
Penelitian ini bertujuan untuk menemukan (1) Aspek kohesi gramatikal dalam kumpulan cerpen konvensi karya A. Mustofa Bisri dan (2) Aspek kohesi leksikal dalam kumpulan cerpen konvensi karya A. Mustofa Bisri. Teknik pengumpulan data yang digunakan adalah simak bebas libat cakap dan catat. Teknik analisis data yang digunakan dalam penelitian ini adalah teknik agih dengan teknik dasar bagi unsur langsung (BUL) dan teknik lanjutan yang digunakan adalah teknik lesap dan teknik ganti. Setelah melakukan penelitian, peneliti menemukan beberapa temuan, sebagai berikut; (1) Kohesi gramatikal dalam penelitian ini ditemukan 109 data dengan rincian sebagai berikut; aspek pengacuan sebanyak 99 data atau 91\%, konjungsi sebanyak 8 data atau 7\%, ellipsis sebanyak 2 data atau 2\%, dan subtitusi 0 data atau 0\%. Sedangkan (2) Kohesi leksikal ditemukan 26 data dengan rincian sebagai berikut; aspek repetisi 6 data atau 23\%, sinonim sebanyak 6 data atau 23\%, antonim 6 data atau 23\%, ekuivalensi sebanayak 4 data atau 15\%. hiponimi sebanyak 2 data atau $8 \%$, dan kolokasi sebanyak 2 data atau $8 \%$. Masing-masing aspek dari kohesi, baik kohesi gramatikal maupun kohesi leksikal ini memiliki peran dalam pembentukan teks dalam wacana, sehingga wacana dapat tersusun secara koheren.
\end{abstract}

Kata Kunci : Kohesi Gramatikal, Kohesi Leksikal, Cerpen

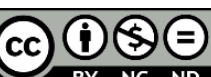

Creative Commons Attribution-NonCommercial-NoDerivatives 4.0 International License 


\section{PENDAHULUAN}

Secara garis besar, sarana komunikasi verbal dibedakan menjadi dua macam, yaitu sarana komunikasi yang berupa bahasa lisan dan sarana komunikasi yang berupa bahasa tulis (Sumarlam, 2010: 1). Dengan demikian, wacana atau tuturan pun dibagi menjadi dua macam, yaitu wacana lisan dan wacana tulis. Wacana adalah satuan bahasa terlengkap dan tertinggi atau terbesar di atas kalimat atau klausa dengan kohesi dan koherensi yang berkesinambungan yang mempunyai awal dan akhir yang nyata disampaikan secara lisan atau tertulis (Tarigan, 2009: 26). Kridalaksana dalam kamus Linguistik (2008: 204) mendefinisikan wacana atau 'Discourse' sebagai satuan bahasa yang lengkap, yaitu dalam hierarki gramatikal merupakan satuan gramatikal tertinggi ataupun terbesar. Wacana direalisasikan dalam bentuk karangan yang utuh seperti novel, buku seri ensiklopedia, paragraf, atau kalimat yang membawa amanat yang lengkap.

Dari uraian di atas, jelas bahwa aspek-aspek yang membentuk kohesi di dalam wacana harus berkesinambungan dan membentuk kesatuan struktur teks agar dapat mendukung koherensi. Apabila urutan progresi pada suatu wacana tidak jelas maka akan menyebabkan ambigu dan tidak koherennya suatu wacana. Suatu ujaran yang tidak jelas urutan awal, tengah dan akhir bukan merupakan wacana. Sebuah wacana dikatakan baik apabila hubungan antarkalimatkalimatnya kohesif dan koheren. Kohesi merujuk pada bentuk, artinya kalimatkalimat yang membangun paragraf itu haruslah berhubungan secara padu. Kohesi dibagi menjadi dua jenis yaitu kohesi gramatikal dan kohesi leksikal. Penanda aspek kohesi gramatikal terdiri dari, pengacuan (referensi), penyulihan (substitusi), penghilangan (elipsis), dan kata penghubung (konjungsi). Penanda aspek kohesi leksikal ini, repetisi (pengulangan), sinonim (persamaan), antonim (lawan kata), hiponim (hubungan bagian atau isi), kolokasi (sanding kata), dan ekuivalensi.

Kohesi gramatikal adalah perpaduan wacana dari segi bentuk atau struktur lahir wacana (Sumarlam, 2010: 40). Penanda aspek gramatikal ini terdiri dari, pengacuan (referensi), penyulihan (substitusi), penghilangan (elipsis), dan kata penghubung (konjungsi). Sedangkan Kohesi leksikal adalah hubungan antarunsur dalam wacana secara semantis (Sumarlam, 2010: 55). Penanda aspek leksikal ini, repetisi (pengulangan), sinonim (persamaan), antonim (lawan kata), hiponim (hubungan bagian atau isi), kolokasi (sanding kata), dan ekuivalensi. Berdasarkan sifatnya wacana digolongkan menjadi dua, yaitu wacana fiksi dan wacana nonfiksi. Salah satu bentuk wacana fiksi adalah wacana prosa yang berupa cerita pendek. Wacana cerita pendek ini dapat dikaji, baik dari segi gramatikalnya maupun dari segi leksikalnya. Cerita pendek merupakan wacana fiksi yang ditulis dalam bentuk naratif yang isinya lebih ringkas dari novel dan sifatnya fiksi yang penulisannya menuntut tingkat kohesi dan koherensi yang tinggi agar menjadi sebuah wacana yang utuh dan padu.

Cerpen merupakan sebuah karya sastra yang di dalamnya berisi cerita yang menggunakan imajinasi. Kadangkala sesuai kejadian nyata tokoh dan penokohannya diubah menjadi rekaan. Makna dalam cerpen mengandung sebuah unsur intrinsik dan ekstrinsik. Sebagian besar para peneliti mencari sebuah karya 
sastra, khususnya cerpen untuk dijadikan sebagai objek kajian. Hal-hal yang perlu diketahui bagi seseorang dalam meneliti atau menganalisis karya sastra fiksi yaitu harus memahami pengalaman yang terdapat dalam cerita dan unsur-unsur elemen pendukung lainnya (Staton, 2012: 9-12). Cerpen tergolong wacana narasi bersifat sugestif yang berfungsi untuk memberikan pengalaman estetis pada pembaca dan bersifat imajinatif. Cerpen memiliki unsur alur cerita yang diceritakan secara selaras agar menciptakan ketertarikan pada cerpen tersebut. Keselarasan alur cerita dibuktikan dengan hubungan antarkalimat dalam cerpen. Hubungan antarkalimat tersebut dapat diwujudkan melalui kohesi maupun koherensi.

Pemilihan wacana cerita pendek Konvensi karya A. Mustofa Bisri dalam penelitian ini mempertimbangkan beberapa aspek. Cerita pendek sebagai sebuah realisasi wacana tulis menuntut agar meniliki tingkat kohesi dan koherensi yang tinggi agar tetap berupa satu kesatuan wacana yang utuh. Penggunaan kohesi aspek gramatikal dan leksikal dalam cerita pendek ini cukup banyak ditemukan. Hal ini menjadikan cerita pendek ini terasa lebih mudah dibaca dan dimengerti alur ceritanya. Dipilihnya cerita pendek karya A. Mustofa Bisri dikarenakan beliau merupakan tokoh sastra yang juga merupakan seorang ulama besar yang sangat produktif dalam menghasilkan karya-karya sastra baik novel maupun cerita pendek.

Secara khusus, alasan pemilihan cerpen karya A. Mustofa Bisri adalah karena gaya penulisan karya sastranya (khususnya cerpen) yang cenderung diekpresikan dalam bentuk dialog campuran (singkat dan panjang) yang memiliki alur dan menggunaan bahasa satire. Hal ini merupakan sebuah keunikan yang mengandung tantangan tersendiri dalam penentuan aspek kohesif dalam wacana. Selanjutnya, analisis teks dalam penelitian ini akan menggunakan seluruh kalimat yang ada pada wacana cerpen tersebut. Penelitian ini diharapkan dapat memberikan hasil analisis yang lebih nyata karena masalah kohesi dan konteks situasi menyangkut masalah ketergantungan unsur-unsur dalam wacana.

Tujuan dari penelitian ini adalah mendeskripsikan dan menganalisis kohesi gramatikal dalam kumpulan cerpen konvensi karya A. Mustofa Bisri. Mendeskripsikan dan menganalisis kohesi leksikal dalam kumpulan cerpen konvensi karya A. Mustofa Bisri. Adapun alasan dalam penelitian ini penulis ingin lebih lanjut mengkaji wujud kohesi gramatikal dan leksikal yang terdapat dalam kumpulan cerpen konvensi karya A. Mustofa Bisri.

\section{METODE}

Jenis penelitian ini adalah penelitian deskriptif kualititatif. Artinya penelitian ini bertujuan untuk mendeskripsikan bentuk-bentuk satuan lingual dalam kohesi gramatikal dan kohesi leksikal dalam kumpulan cerpen konvensi karya A. Mustofa Bisri, sedangkan metode penelitian dalam penelitian ini menggunakan metode analisis isi (content analysis). Fraenkel dan Wallen (2008: 483) menyatakan analisis isi adalah teknik yang dapat digunakan peneliti untuk mengkaji perilaku manusia secara tidak langsung melalui analisis terhadap 
komunikasi mereka seperti : buku teks, esay, koran, novel, artikel majalah, lagu, gambar iklan dan semua jenis komunikasi yang dapat dianalisis.

Dalam penelitian ini, teknik pengumpulan data yang digunakan adalah simak bebas libat cakap dan catat. Sudaryanto (2015: 204) menyatakan bahwa teknik simak bebas libat cakap merupakan teknik pengambilan data yang memposisikan peneliti tidak terlibat dalam dialog atau percakapan yang menjadi subjek penelitian. Penelitian ini menggunakan teknik simak bebas libat cakap karena peneliti tidak terlibat dalam dialog, tetapi hanya berperan sebagai pemerhati tuturan penutur.

Pada tahap analisis data penelitian ini mengunakan metode agih. Metode agih menggunakan alat penentu unsur bahasa itu sendiri (Sudaryanto 2015: 15). Meotode agih digunakan terutama dalam mengklasifikasikan data berupa relasi sintaksis dan relasi semantis yang mengacu pada teori Role and Reference Grammar (RRG) yang membagi empat aspek mengenai peran semantis, yaitu (1) semantis predikat/verba, (2) inherent lexical content frasa nomina, (3) pemilihan perspektif (Actor Dan Undergoer), Dan (4) Valensi, Ketransitifan, Dan Jumlah Macrorole.

Sudaryanto (2015: 145) menyatakan bahwa teknik dalam menganalisis data berdasarkan metode padan dan agih dapat dibedakan menjadi dua, yakni teknik dasar dan teknik lanjutan. Teknik dasar metode agih disebut teknik bagi unsur langsung atau teknik BUL. Sementara itu, teknik lanjutan pada metode agih terbagi menjadi tujuh macam, yakni teknik lesap, teknik ganti, teknik perluas, teknik sisip, teknik balik, teknik pengubahan wujud, dan teknik pengulangan (Sudaryanto, 2015: 146).

Sehubungan dengan hal tersebut, teknik BUL ini dipakai untuk menganalisis bentuk Kohesi Gramatikal dan Leksikal dalam Kumpulan Cerpen Konvensi Karya A. Mustofa Bisri, kemudian dilanjutkan dengan teknik teknik lanjutan, teknik lanjutan yang peneliti gunakan adalah lesap dan teknik ganti.

\section{HASIL DAN PEMBAHASAN}

\section{Hasil}

Kumpulan cerpen Konvensi merupakan terbitan pertama bulan November 2018 yang ditulis dengan waktu yang lama sehingga pada tahun 2019 baru bisa diterbitkan. Penulisan karya tersebut berdasarkan keadaan nyata yang digunakan sebagai ide dari kumpulan cerepen. Penulisan cerpen Konvensi menggambarkan kedalamaan, kepekaan, dan kesederhanaan A. Mustofa Bisri dengan menggambarkan kenyataan yang ada dalam masyarakat dan negeri sebagai ide dalam menulis. Dari 219 halaman terdapat 135 data kohesi dalam Kumpulan Cerpen Konvensi Karya A. Mustofa Bisri yang terbagai ke dalam kohesi graatikal yaitu 99 pengacuan, 2 elipsis, 8 konjungsi. Sementara itu kohesi leksikal ditemukan antara lain : 6 Repetisi, 6 sinonim, 2 hiponim, 6 antonim, 2 kolokasi, 4 ekuivalensi. 
Tabel 1. Jumlah Kohesi Gramatikal dalam Kumpulan Cerpen Konvensi Karya A. Mustofa Bisri

\begin{tabular}{clc}
\hline No & Aspek Kohesi Gramatikal & Jumlah Temuan dalam Cerpen \\
\hline 1 & Referensi (pengacuan) & 99 data \\
2 & Konjungsi & 8 data \\
3 & Elipsis & 2 data \\
4 & Substitusi & 0 data \\
\hline & Jumlah Total & 109 data
\end{tabular}

Berdasarkan tabel jumlah kohesi gramatikal dalam Cerpen Konvensi karya A. Mustofa Bisri terdapat beberapa aspek gramatikal dengan rincian sebagai berikut: (1) pengacuan atau referensi 99 data (2) konjungsi 8 data, (3) elipsis sebanyak 2 data dan (4) subtitusi 0 data atau tidak ditemukannya aspek subtitusi. Keseluruhan data tabel tersebut jika dikonversi atau dipersentasekan kedalam bentuk diagram lingkaran maka akan terlihat sebagai berikut:

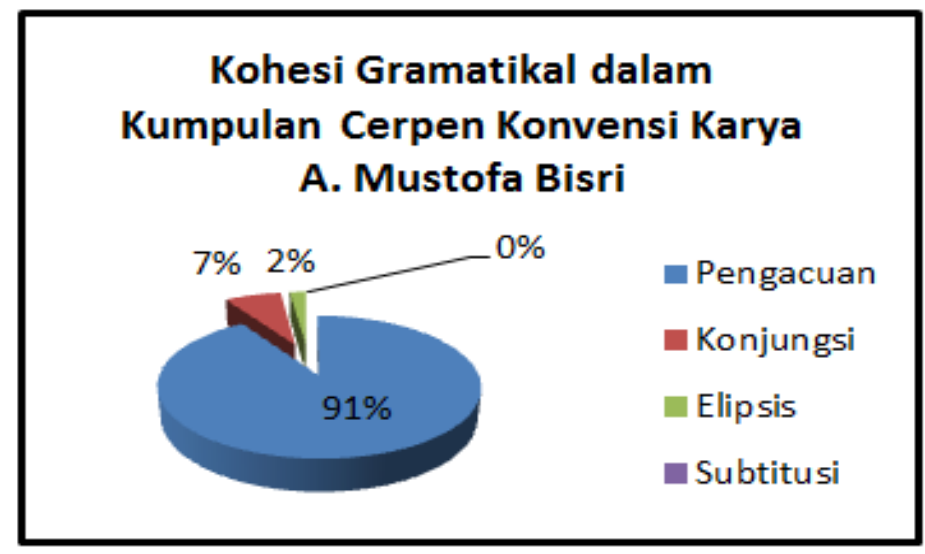

Gambar 1. Persentase Kohesi Gramatikal

Berdasarkan diagram lingkaran di atas maka jumlah kohesi gramatikal hasil persentase dengan rincian sebagai berikut : (1) pengacuan atau referensi sebanyak $91 \%$ data (2) konjungsi sebanyak 7\% data, (3) elipsis sebanyak $2 \%$ data dan (4) subtitusi $0 \%$ data.

Tabel 2. Jumlah Kohesi Leksikal dalam Kumpulan Cerpen Konvensi karya A. Mustofa Bisri

\begin{tabular}{clc}
\hline No & \multicolumn{1}{c}{ Aspek Kohesi Leksikal } & $\begin{array}{c}\text { Jumlah Temuan dalam } \\
\text { Cerpen }\end{array}$ \\
\hline 1 & Repetisi (pengulangan) & 6 data \\
2 & Sinonim & 6 data \\
3 & Antonim & 6 data \\
4 & Ekuivalensi & 4 data \\
5 & Hiponim & 2 data \\
6 & Kolokasi & 2 data \\
\hline & Jumlah Total & 26 data
\end{tabular}


Berdasarkan tabel jumlah keseluruhan kohesi leksikal dalam Cerpen Konvensi karya A. Mustofa Bisri terdapat 26 data dengan rincian sebagai berikut: (1) Refetisi (Pengulangan) sebanyak 6 data, (2) Sinonim sebanyak 6 data, (3) Antonim sebanyak 6 data, (4) Ekuivalensi sebanyak 4 data, (5) Hiponim sebanyak 2 data, dan (6) kolokasi sebanyak 2 data. Secara keseluruhan dalam penulisan Cerpen Konvensi karya A. Mustofa Bisri baik karena peneliti tidak banyak menemukan perlawanan, persamaan dan pengulangangan kata dalam tuturanya hal ini membuat cerpen konvensi bahasanya tidak ambigu dan mudah dipahami oleh pembaca. Keseluruhan data tabel tersebut jika di konversi atau persentasekan kedalam bentuk diagram lingkaran maka akan terlihat sebagai berikut :

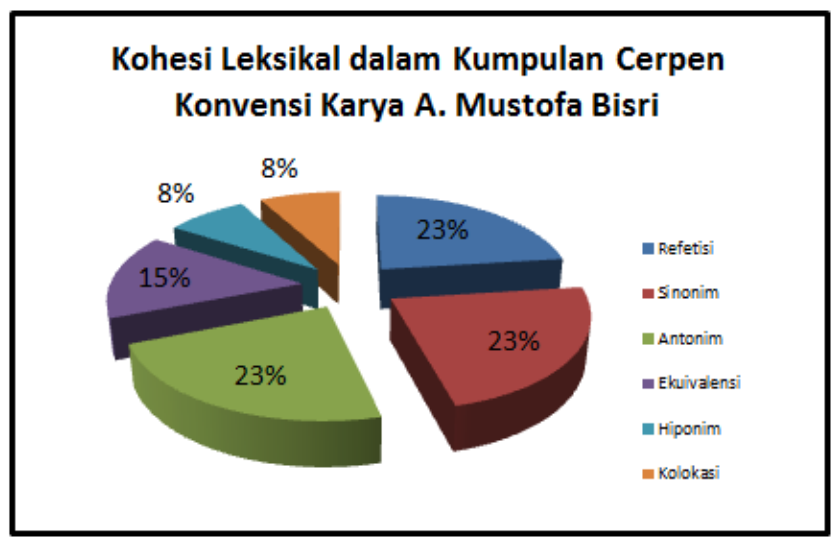

\section{Gambar 2. Persentase Kohesi Leksikal}

Berdasarkan diagram lingkaran di atas maka jumlah kohesi gramatikal hasil persentase dengan rincian sebagai berikut : (1) Refetisi (Pengulangan) sebanyak 23\%, (2) Sinonim sebanyak 23\%, (3) Antonim sebanyak 23\%, (4) Ekuivalensi sebanyak 15\%, (5) Hiponim sebanyak 8\%, dan (6) kolokasi sebanyak $8 \%$.

\section{Pembahasan}

Dari hasil penelitian di atas tampak bahwa dalam Cerpen Konvensi karya A. Mustofa Bisri terdapat beberapa aspek gramatikal dari beberapa aspek tersebut pengacuan atau referensi yang paling mendominasi yaitu sebanyak 92 data jika dipersentasekan sebanyak 91\%, hal ini mudah dipahami karena wacana ini berupa cerpen yang tersusun atas dialog-dialog yang saling berhubungan atau memiliki keterkaitan satu sama lainnya, dengan beberapa tokoh/karakter yang relatif sama dari awal hingga akhir cerita, sehingga untuk penyebutan para karakter (setelah penyebutan nama karakter), penulis cerpen lebih banyak menggunakan pronomina persona. Kemudian konjungsi sebanyak 8 data atau 7\%, selanjutnya elipsis sebanyak 2 data atau $2 \%$ dan subtitusi 0 data atau $0 \%$. Dalam penelitian ini peneliti tidak menemukan aspek subtitusi, tidak ditemukannya aspek subtitusi dalam wacana cerpen tersebut karena penggunaan bahasa dalam cerpen tersebut cukup lugas dan mudah dipahami oleh pembaca sehingga tidak terjadi penyulingan atau perubahan kata dalam tuturannya. 
Sementara itu, aspek leksikal dari hasil penelitian peneliti menemukan refetisi sebanyak 6 data jika dipersentasikan sebanyak 23\% kemudian sinonim 6 data atau 23\%, antonim sebanyak 6 data atau 23\%, ekuivalensi sebanyak 4 data atau $15 \%$, hiponim sebanyak 2 data atau $8 \%$, dan kolokasi sebanyak 2 data atau $8 \%$. Secara keseluruhan dalam penulisan Cerpen Konvensi karya A. Mustofa Bisri baik karena peneliti tidak banyak menemukan perlawanan, persamaan dan pengulangangan kata dalam tuturanya hal ini membuat cerpen konvensi bahasanya tidak ambigu dan mudah dipahami oleh pembaca.

\section{SIMPULAN}

Dari deskripsi hasil analisis data maka disimpulkan dalam wacana cerpen konvensi ditemukan tigas aspek kohesi gramatikal, yaitu referensi, ellipsis, dan konjungsi. Kohesi gramatikal ini didominasi oleh penggunaan aspek referensi atau pengacuan, yakni sebanyak 99 pengacuan, yang terdiri atas pengacuan persona sebanyak 92, pengacuan demonstratif sebanyak 6 data, dan pengacuan komparatif 1 data, kemudian, konjungsi yaitu sebanyak 8 data, ellipsis atau pelesapan 2 data, dan terakir subtitusi 0 data. Jadi, secara keseluruhan, kohesi gramatikal dalam wacana cerpen konvensi berjumlah 109. Apabila dipersentasikan maka dalam kohesi gramatikal terdapat sebanyak $91 \%$ aspek referensi, $7 \%$ aspek konjungsi, $2 \%$ aspek elipsis, dan $0 \%$ aspek subtitusi.

Dalam wacana cerpen konvensi juga ditemukan keenam jenis kohesi leksikal, yakni repetisi, sinonim, hiponim, antonimi, kolokasi dan ekuivalensi. Repetisi dalam wacana cerpen ini terdapat dalam 6 data, sinonim sebanyak 6 data, antonim sebanyak 6 data, ekuivalensi sebanayak 4 data, hiponimi sebanyak 2 data, dan terakhir kolokasi sebanyak 2 data. Jadi, secara keseluruhan kohesi leksikal dalam wacana cerpen ini berjumlah 26. Apabila dipersentasikan maka dalam kohesi leksikal terdapat sebanyak $23 \%$ repetisi, $23 \%$ sinonimi, $23 \%$ antonimi, $15 \%$ ekuivalensi, $8 \%$ hiponim, dan $8 \%$ kolokasi.

\section{DAFTAR PUSTAKA}

Bisri, A. M. (2018). Konvensi: Kumpulan cerpen. Yogyakarta: Diva Press.

Frankel, J. P., \& Wallen, N. E. (2008). Design and Evalute Research in Education. [Online]. Dikases dari http://eprints.uny.ac.id /id/eprint/65553. Diunduh pada 04/07/20202.

Kridalaksana, H. (2008). Kamus linguistik. Jakarta: Gramedia Pustaka Utama.

Staton, R. (2012). Teori fiksi robert staton. Yogyakarta: Pustaka Pelajar.

Sudaryanto. (2015). Metode dan aneka teknik analisis bahasa: Pengantar penelitian wahana kebudayaan secara linguistis. Yogjakarta: Sanata Dharma University Press.

Sumarlam. (2010). Teori dan praktik analisis wacana. Solo: Buku Katta.

Tarigan, H. G. (2009). Pengajaran wacana. Bandung: Angkasa.

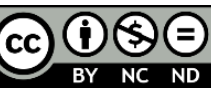

